\title{
Novel repellents for the blood-sucking insects Rhodnius prolixus and Triatoma infestans, vectors of Chagas disease
}

\author{
Melanie Ramírez ${ }^{1}$, Mario I. Ortiz ${ }^{1}$, Pablo Guerenstein ${ }^{2,3}$ and Jorge Molina ${ }^{1 *}$
}

\begin{abstract}
Background: Studying the behavioral response of blood-sucking disease-vector insects to potentially repellent volatile compounds could shed light on the development of new control strategies. Volatiles released by human facial skin microbiota play different roles in the host-seeking behavior of triatomines. We assessed the repellency effect of such compounds of bacterial origin on Triatoma infestans and Rhodnius prolixus, two important vectors of Chagas disease in Latin America.

Methods: Using an exposure device, insects were presented to human odor alone (control) and in the presence of three individual test compounds (2-mercaptoethanol, dimethyl sulfide and 2-phenylethanol, the latter only tested in R. prolixus) and the gold-standard repellent NN-diethyl-3-methylbenzamide (DEET). We quantified the time the insects spent in the proximity of the host and determined if any of the compounds evaluated affected the behavior of the insects.

Results: We found volatiles that significantly reduced the time spent in the proximity of the host. These were 2-phenylethanol and 2-mercaptoethanol for R. prolixus, and dimethyl sulfide and 2-mercaptoethanol for T. infestans. Such an effect was also observed in both species when DEET was presented, although only at the higher doses tested.

Conclusions: The new repellents modulated the behavior of two Chagas disease vectors belonging to two different triatomine tribes, and this was achieved using a dose up to three orders of magnitude lower than that needed to evoke the same effect with DEET. Future efforts in understanding the mechanism of action of repellent compounds such as 2-mercaptoethanol, as well as an assessment of their temporal and spatial repellent properties, could lead to the development of novel control strategies for these insect vectors, refractory to DEET.
\end{abstract}

Keywords: Semiochemicals, Citrobacter, Skin microbiota, Volatile organic compounds, DEET

\section{Background}

Most vectors of human infectious diseases are bloodsucking insects, and therefore, many of those diseases could be managed by the use of insect-vector control strategies [1]. For example, it is strongly advised that

\footnotetext{
*Correspondence: jmolina@uniandes.edu.co

${ }^{1}$ Centro de Investigaciones en Microbiología y Parasitología Tropical (CIMPAT), Departamento de Ciencias Biológicas, Universidad de los Andes, Bogotá, Colombia

Full list of author information is available at the end of the article
}

people living in or visiting regions populated by insects that feed on blood, such as mosquitoes, protect themselves using insect repellents [2]. Independently of its mechanism of action, the final effect of a repellent is to cause an insect to make oriented movements away from its source. The expected result is to disrupt the hostseeking behavior of the threatening insect [3-5].

Triatomine bugs (Hemiptera: Reduviidae: Triatominae) feed on the blood of vertebrates and are vectors of the protozoan parasite Trypanosoma cruzi, the etiological agent of Chagas disease, also known as American

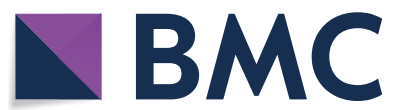

(c) The Author(s) 2020. This article is licensed under a Creative Commons Attribution 4.0 International License, which permits use, sharing, adaptation, distribution and reproduction in any medium or format, as long as you give appropriate credit to the original author(s) and the source, provide a link to the Creative Commons licence, and indicate if changes were made. The images or other third party material in this article are included in the article's Creative Commons licence, unless indicated otherwise in a credit line to the material. If material is not included in the article's Creative Commons licence and your intended use is not permitted by statutory regulation or exceeds the permitted use, you will need to obtain permission directly from the copyright holder. To view a copy of this licence, visit http://creativeco mmons.org/licenses/by/4.0/. The Creative Commons Public Domain Dedication waiver (http://creativecommons.org/publicdomain/ zero/1.0/) applies to the data made available in this article, unless otherwise stated in a credit line to the data. 
trypanosomiasis [6]. The vast majority of the extant 149 species of triatomines are found in Latin American countries, where 68 triatomine species have been found infected with T. cruzi, and more than 150 species of domestic and wild mammals have been found to carry the parasite [7-12]. However, few triatomine species are recognized as competent vectors, and only approximately five species are considered very important vectors for humans: Rhodnius prolixus Stål, 1859 (inhabiting mainly Colombia and Venezuela), Triatoma infestans (Klug, 1834) (inhabiting mainly Peru, Bolivia, Paraguay and Argentina), T. dimidiata (Latreille, 1811) (inhabiting Mexico and Central America), T. brasiliensis Neiva, 1911 and Panstrongylus megistus (Burmeister, 1835) (both found mainly in Brazil) [8, 13]. Although there are many routes of $T$. cruzi transmission (i.e. oral, blood transfusion, mother to child), the vectorial infection can occur if, after taking a large blood meal, the insect defecates on the host skin and the feces carrying infective forms of T. cruzi enter the blood stream through the wound or any mucous tissue [8]. Since its discovery by Carlos Chagas, controlling vectorial transmission has been the most suitable method to prevent Chagas disease, which affects approximately 7 million people worldwide [14].

Historically, most research on repellents has focused on mosquitoes over other blood-sucking arthropods such as triatomines $[4,15-21]$. This tendency to focus on mosquito-repellent research is not surprising considering the higher mortality and morbidity due to mosquito-borne diseases compared to that of Chagas disease [22-24]. For almost six decades, NN-diethyl-3-methylbenzamide, known as DEET, has been the most common mosquito repellent used worldwide [25]. In fact, the effectiveness of DEET against all groups of biting arthropods, triatomines included, has granted it the title of the gold standard among repellents $[4,5]$. However, compared with mosquitoes and other blood-sucking arthropods, triatomines have a lower sensitivity to this repellent $[19,26]$. Studies with $R$. prolixus and $T$. infestans have revealed that whether the host is present or not, only high doses (i.e. >90\%) have a repellent effect, making DEET rather impractical for reducing human-triatomine contacts $[15$, 27-30]. In addition to these and other related findings in triatomines (i.e. DEET pre-exposure adaptation, DEET repellency in pyrethroid resistant colonies and the effect of nitric oxide on the sensory detection of DEET) [20,31, 32 ], other studies have explored natural repellents such as essential oils, aiming at finding alternatives to DEET and other synthetic repellents [18, 21, 23, 33-36].

A decade of research has shown that volatile organic compounds (VOCs) from human skin and of microbial origin play a role in the behavioral responses of some blood-sucking insects [37]. For example, VOCs produced by skin bacteria are important cues for the malaria vector Anopheles gambiae to identify hosts as human and even to confer specificity to certain body regions on which mosquitos tend to bite more [37-42]. Moreover, previous studies carried out in our laboratory have demonstrated the role that VOCs released by human facial skin microbiota play in the host-seeking behavior of $R$. prolixus [43-45]. Thus, Tabares et al. [43] showed, in dual choice olfactometer experiments, that VOCs produced in vitro by some skin bacteria (at specific growth phases) have an attractive effect on $R$. prolixus. The authors also reported odor-source avoidance when some other bacteria VOCs were presented, such as those produced by Citrobacter koseri (Enterobacteriaceae). Thus, in this case, insects consistently chose the negative control (i.e. culture medium without bacteria) over the culture medium with bacteria VOCs. These two findings, the attractive and avoidance behavioral effects, contrast with those obtained using even other bacterial VOCs to which $R$. prolixus did not respond at all [43].

These studies show that the behavioral response of triatomines to the mix of VOCs produced by the skin microbiota is very complex [43]. Moreover, the role of individual bacterial volatiles from mixtures evoking avoidance is still unknown, and their potential use as repellents deserves further investigation. In this study, we asked whether individual VOCs released by cultures of $C$. koseri, which evokes avoidance, could affect the behavior of kissing bugs in the proximity of a human host causing, for example, a repellent effect. Furthermore, we investigated whether this potential effect could be equivalent to that evoked by the well-known repellent DEET. Thus, using an exposure device, we investigated in $R$. prolixus and $T$. infestans the repellent effect of three compounds which are structurally similar to compounds identified from cultures of C. koseri [43]; 2-mercaptoethanol, 2 -phenylethanol and dimethyl sulfide. We compared the repellency effectiveness of these compounds at different doses with that obtained with DEET.

\section{Methods}

Insects

Adults of $R$. prolixus and third-instar nymphs of $T$. infestans from our laboratory colonies were used (the reason for using different life stages for the two species relates to insect availability). The $R$. prolixus colony originated from wild populations from San Juan de Arama, Meta Department (Northeast of Colombia), and has been maintained at the Centro de Investigaciones en Microbiología y Parasitología Tropical (CIMPAT), Universidad de los Andes (Bogotá, Colombia) since 1979, while the T. infestans colony originated from wild populations 
from Chaco Province (Northeast of Argentina; provided by the Centro de Referencia de Vectores, CeReVe-Argentina), has been maintained at the Centro de Investigacion Cientifica y de Transferencia Tecnologica a la Produccion (CICyTTP, Diamante, Argentina) since 2011, and has been receiving new wild insects from the same region almost every year for the last four years. Insects were fed on hens every two weeks and maintained under an artificial 12:12 h (light:dark) illumination regime at a controlled temperature and humidity $\left(27 \pm 2{ }^{\circ} \mathrm{C}, 75 \pm 10 \%\right.$ $\mathrm{RH})$.

For experiments, insects were separated from the colony after molting and starved for at least 20 days for $R$. prolixus and 30 days for $T$. infestans. Experiments were video recorded using a DCR-SR 200 camera (Sony Corp., Tokio, Japan) or an A1633 iPhone camera (Apple Inc., Cupertino, USA) and performed during the early scotophase at $24.5 \pm 0.5{ }^{\circ} \mathrm{C}$ in a dark (or red-light illuminated) room. Experiments with $R$. prolixus were performed at CIMPAT, Universidad de los Andes, and experiments with T. infestans were carried out at Laboratorio de Estudio de la Biología de Insectos (LEBI), CICyTTP. Insects were tested individually and used only once.

\section{Repellency tests}

To test the effect of structurally similar compounds produced in vitro by bacteria previously isolated from human facial skin [43], an exposure device modified from Zermoglio et al. [15] was used and is shown in Fig. 1. In brief, a polystyrene tube was divided into three zones: host, intermediate and refuge zones. An insect was placed in the refuge zone, and after a $5 \mathrm{~min}$ adaptation time, the experiment started with the opening of a gate, allowing

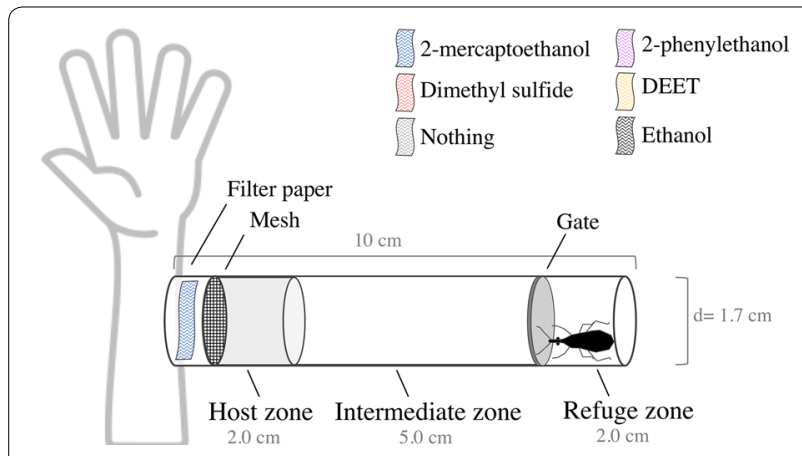

Fig. 1 Exposure device with live host to test repellent effect of different compounds on Rhodnius prolixus and Triatoma infestans. Drawing not to scale. A polystyrene tube $(10.0 \times 1.7 \mathrm{~cm}$, length $\times$ diameter, respectively) was divided in three zones: host, intermediate and refuge zone. At the end of the host zone a mesh allows transmission of stimuli released by the host (including VOCs alone or with repellent compounds), but avoid that insects could bite the host the insect to freely move from the refuge to the other two zones. Insects attracted by the stimuli from the forearm of a volunteer walked to the host zone, while mesh prevented them from biting the volunteer. Experiments lasted $5 \mathrm{~min}$. The exposure device allowed us to quantify the time the insect spent near the host in the presence or absence of the compounds tested.

To avoid different VOC profiles, we always tested the same forearm of only one volunteer. During the period of time that experiments were carried out, the volunteer was asked to avoid to use any soap when taking a shower, to refrain from drinking alcohol or eating any spicy food and using any perfumed cosmetics or any skin products. The volunteer does not smoke, was free from chronic illnesses and not using any medication on a regular basis.

Ten insects per treatment were used; these were randomly assigned to each treatment. Treatments for experiments with $R$. prolixus consisted of increasing concentrations ( $\mathrm{vol} / \mathrm{vol})$ of 2-mercaptoethanol $(0.0015625 \%$, $0.003125 \%, 0.00625 \%, 0.0125 \%, 0.025 \%, 0.05 \%$ and $0.1 \%$ ), dimethyl sulfide $(0.00625 \%, 0.0125 \%, 0.025 \%, 0.05 \%$ and $0.1 \%)$, 2-phenylethanol (0.025\%, $0.05 \%, 0.1 \%$ and $0.2 \%)$, and DEET (10\%, 50\% and 90\%). Treatments for experiments with $T$. infestans consisted of increasing concentrations ( $\mathrm{vol} / \mathrm{vol})$ of 2-mercaptoethanol $(0.00625 \%$, $0.025 \%, 0.1 \%$ and $1 \%)$, dimethyl sulfide $(0.1 \%$ and $1 \%)$, and DEET (90\%). The tested compounds were $\geq 99 \%$ pure (Merck, Darmstadt, Germany), while DEET was $>97 \%$ pure (Sigma-Aldrich, Darmstadt, Germany). Dimethyl sulfide and 2-mercaptoethanol solutions were diluted in distilled water, while 2-phenylethanol and DEET were diluted in ethanol. We performed frequent control tests before the beginning of treatment tests: host stimuli without any test compound ("host alone" a to d, see below) and host stimulus plus just ethanol ("host plus ethanol", see below). The test odor stimulus consisted of a $10 \mu \mathrm{l}$ solution (or just solvent for the controls) loaded onto a filter paper strip $(1.0 \times 3.0 \mathrm{~cm})$. In the case of DEET, $10 \mu \mathrm{l}$ or $50 \mu \mathrm{l}$ solutions (where indicated) were used. The paper strip with the test solution or solvent control was carefully placed in the space between the host's forearm and the mesh in the tube. Neither the host's skin nor the insects were in direct contact with the compounds tested.

\section{Data analysis and statistics}

We carried out nonparametric statistical tests to determine whether the compounds influenced the time that the insect spent in the host proximity. Prism software (GraphPad, v. 7.0a) was used to perform Kruskal-Wallis ANOVAs. Significant results $(P<0.05)$ were followed by Dunnett's tests to compare the responses of each group with all other groups. 
2-Mercaptoethanol

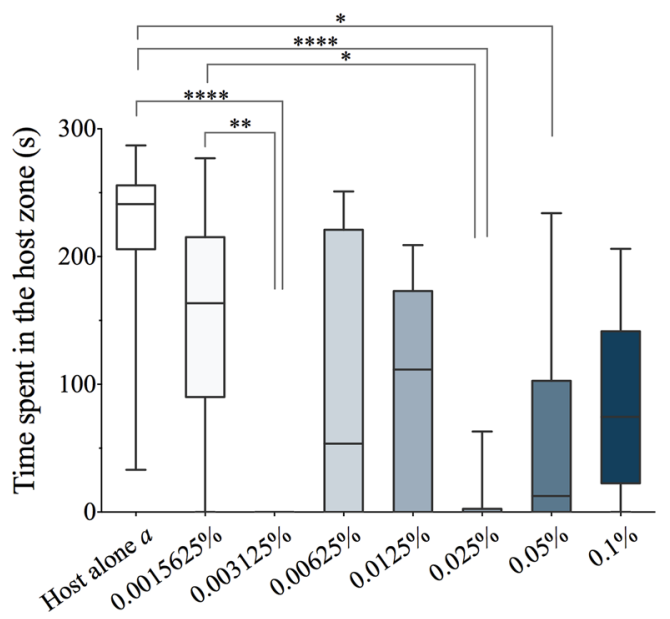

2-Phenylethanol

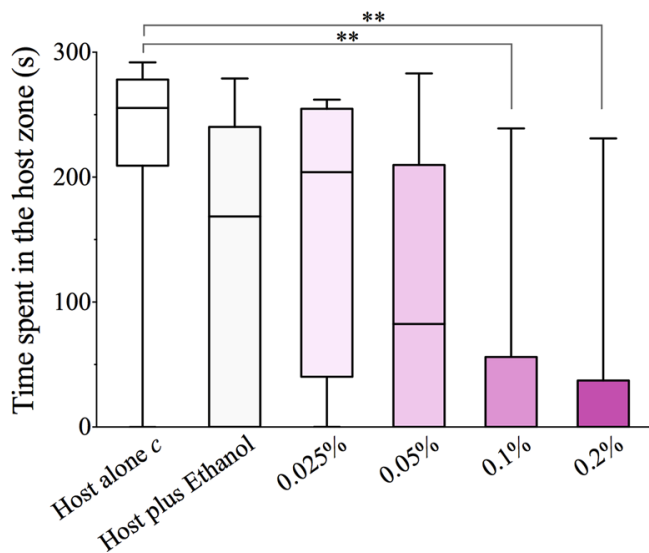

Dimethyl sulfide

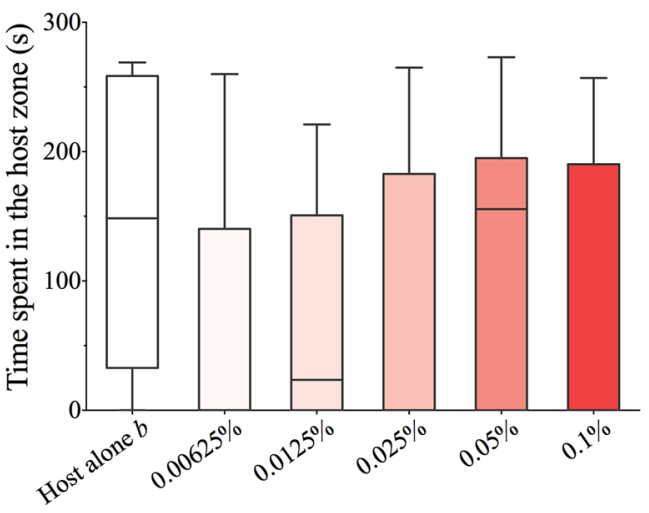

DEET

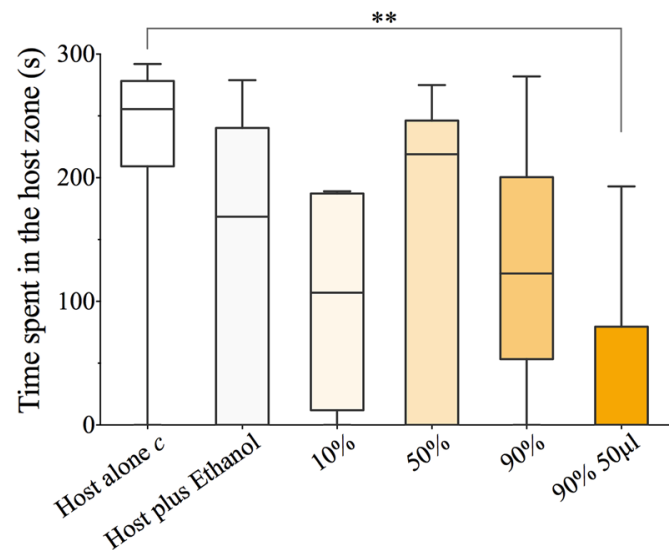

Fig. 2 Box plots showing the effect of different doses of the test compounds on the time that Rhodnius prolixus spent in the proximity of a vertebrate host when the insects were exposed to 2-mercaptoethanol, dimethyl sulfide, 2-phenylethanol, and DEET (median, 25th and 75th percentiles are shown; whiskers denote minimum and maximum values). Asterisks denote significant differences among treatments according to Dunnett's multiple comparison test $\left({ }^{*} P<0.05 ;{ }^{* *} P<0.01,{ }^{* * *} P<0.0001\right)$. Host alone $\mathrm{a}, \mathrm{b}$ and $\mathrm{c}$ are control repetitions consisting of exposure to the forearm of the host in the absence of any test compound

\section{Results}

In this study, we assessed the repellency of VOCs released by the skin bacterium $C$. koseri against $R$. prolixus and $T$. infestans. For this, 240 starved adult $R$. prolixus and 90 starved T. infestans nymphs were assayed.

In the absence of test compounds, $R$. prolixus spent $81.6 \%$ ("host alone" a), 49.5\% ("host alone" b), and 85.2\% ("host alone" c) of the total experimental time within the host zone (Fig. 2, white boxes). In the case of T. infestans, insects spent $59 \%$ ("host alone" d) of the total time in the host zone (Fig. 3, white boxes). However, when certain doses of 2-mercaptoethanol, 2-phenylethanol or DEET were added, the time that adult $R$. prolixus spent in the host zone was significantly lower (Kruskal-Wallis H-test: $\chi^{2}=38.29, d f=7, P<0.0001$; $\chi^{2}=21.4, d f=5, P=0.0007 ; \chi^{2}=17.48, d f=5, P=0.0037$, respectively) (Fig. 2). Likewise, certain doses of 2-mercaptoethanol and DEET considerably reduced the time that T. infestans nymphs stayed near the host (Kruskal-Wallis H-test: $\chi^{2}=22.25, d f=4, P=0.0002$ and $\chi^{2}=17.04, d f=2$, $P=0.0002$, respectively) (Fig. 3). It should be noted that Dunnett's multiple comparison tests showed no differences between the times in the host zone for treatments in which the compounds were dissolved in ethanol and those for the control "host plus ethanol". However, a significant difference was found when comparing the effect of the test compounds with that of host alone (Table 1).

The time spent by $R$. prolixus near the host did not differ statistically from the control when dimethyl sulfide was tested (Kruskal-Wallis H-test: $\chi^{2}=8.282, d f=5$, $P=0.1414)$. In contrast, dimethyl sulfide did reduce the 

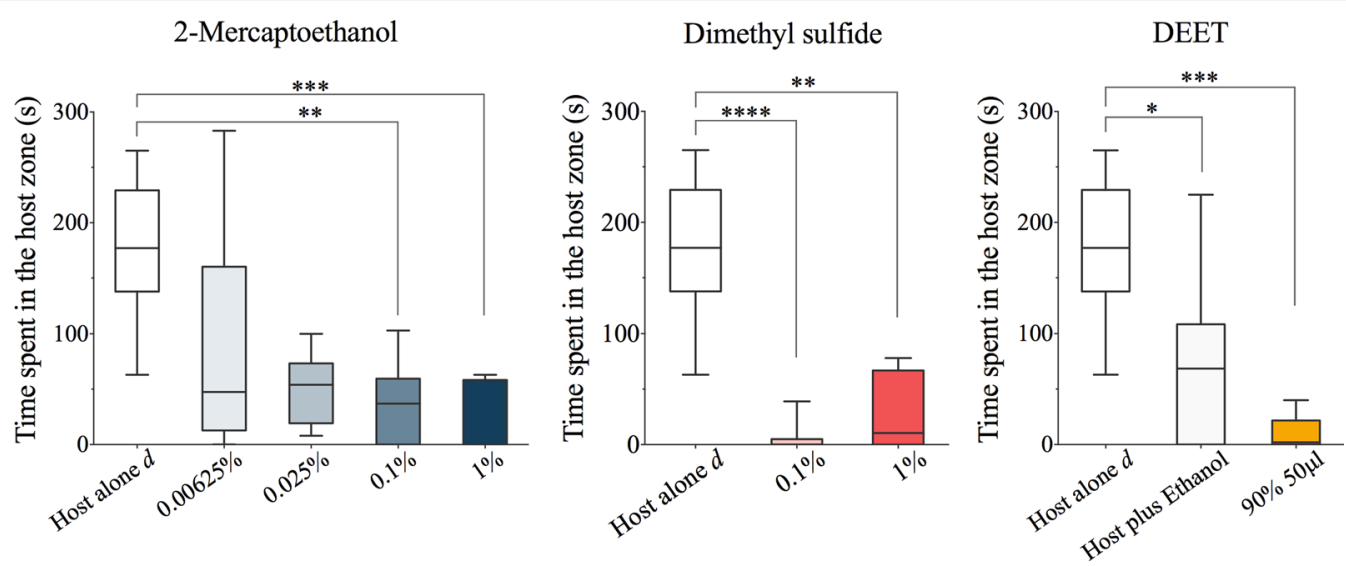

Fig. 3 Box plots showing the effect of different doses of the test compounds on the time that Triatoma infestans spent in the proximity of a vertebrate host when the insects were exposed to 2-mercaptoethanol, dimethyl sulfide, and DEET (median, 25th and 75th percentiles are shown; whiskers denote minimum and maximum values). Asterisks denote significant differences among treatments according to Dunnett's multiple comparison test $\left({ }^{*} P<0.05 ;{ }^{* *} P<0.01,{ }^{* *} P<0.001,{ }^{* * *} P<0.0001\right)$. Host alone $d$ refers to a control consisting of exposure to the forearm of the host in the absence of any test compound

Table 1 Summary of the multiple comparisons tests that resulted in statistically significant differences $(P<0.05)$, showing treatments that reduced the time the insects spent in the host zone with respect to the controls

\begin{tabular}{|c|c|c|c|c|c|}
\hline Chagas disease vector & VOC tested & Kruskal-Wallis test & Comparison test & $\begin{array}{l}\text { Dunn's multiple } \\
\text { test } P \text {-value }\end{array}$ & Effective dose \\
\hline \multirow[t]{8}{*}{ R.prolixus } & 2-mercaptoethanol & $<0.0001$ & Host alone a vs $0.003125 \%$ & $<0.0001$ & Low \\
\hline & & & Host alone a vs $0.025 \%$ & $<0.0001$ & \\
\hline & & & Host alone a vs $0.05 \%$ & 0.0148 & \\
\hline & & & $0.003125 \%$ vs $0.0015625 \%$ & 0.0081 & \\
\hline & & & $0.025 \%$ vs $0.0015625 \%$ & 0.0392 & \\
\hline & 2-phenylethanol & 0.0007 & Host alone c vs $0.1 \%$ & 0.0036 & Low \\
\hline & & & Host alone c vs $0.2 \%$ & 0.0033 & \\
\hline & DEET & 0.0037 & Host alone c vs DEET $90 \% 50 \mu \mathrm{ll}$ & 0.0010 & High \\
\hline \multirow[t]{6}{*}{ T. infestans } & 2-mercaptoethanol & 0.0002 & Host alone $\mathrm{d}$ vs $0.1 \%$ & 0.0019 & Low \\
\hline & & & Host alone d vs 1\% & 0.0001 & \\
\hline & Dimethyl sulfide & $<0.0001$ & Host alone $\mathrm{d}$ vs $0.1 \%$ & $<0.0001$ & Low \\
\hline & & & Host alone $d$ vs $1 \%$ & 0.0058 & \\
\hline & DEET & 0.0002 & Host alone $d$ vs host plus ethanol & 0.0346 & High \\
\hline & & & Host alone d vs DEET 90\% $50 \mu \mathrm{l}$ & 0.0001 & \\
\hline
\end{tabular}

time that the $T$. infestans nymphs spent near the forearm (Kruskal-Wallis H-test: $\chi^{2}=21.05, d f=2, P<0.0001$ ). A summary of the statistically significant results of the multiple comparisons tests is shown in Table 1.

\section{Discussion}

Our results provide evidence that some VOCs released by the opportunistic skin bacterium $C$. koseri interfere with the host-seeking behavior of $R$. prolixus and $T$. infestans, two important vectors of Chagas disease. In control tests where just a host is presented, $R$. prolixus adults and T. infestans nymphs move their antennae in a triangulation fashion [46, 47], and in just a few seconds, usually walk towards the host, extend their proboscis and try to bite the forearm. However, when the compounds tested are added to the stimuli of the host, the behavior of the bugs changes; the time spent near the human host is considerably reduced (Figs. 2, 3). An additional movie file (Additional file 1: Video S1) shows that both species rapidly walk away from the stimulus source after approaching it, which suggests a clear repellent effect of these compounds (even when attractive stimuli such as heat and host VOCs are present). The methodology used in this work (based on that by Zermoglio et al. [15]) 
provides a fast and direct way to test the effect of candidate repellent compounds near a vertebrate host.

As it has been shown for mosquitos, $R$. prolixus is attracted by some VOCs released by human face skin microbiota [43-45]. These results provide further support for the hypothesis that the host-seeking behavior of triatomines is actually a tripartite relationship (host, vector and microbiota) and could be the result of the close vertebrate-vector coevolutive history. The observed repellency to VOCs produced by $C$. koseri may be understood if the natural occurrence of the bacterium is considered: C. koseri is a gram-negative bacillus of the family Enterobacteriaceae commonly found in animal intestines, soils, water, sewage and contaminated food, and it is widely recognized for causing devastating meningitis in neonates and severe infections in immunosuppressed patients [48]. This bacterium is not part of the healthy human skin microbiota; human skin isolations where this bacillus is found are commonly from sick patients [48, 49] so that, these volatiles could signal an unhealthy individual to the bugs.

Interestingly, it is not new that the VOC signature of the genus Citrobacter influences the chemotactic orientation behavior of blood-seeking insects. Ponnusamy et al. [50] found that VOCs released by C. freundii were attractive to gravid females of Aedes (Stegomyia) aegypti and Ae. (Stegomyia) albopictus, two mosquito species which are important vectors of arboviruses [51]. It was also suggested that Citrobacter VOCs, in synergy with other compounds present in water, give mosquitos information about the quality of the oviposition sites [50]. In the bloodsucking stable fly Stomoxys calcitrans, Romero et al. [52] showed that VOCs released by C. freundii induce oviposition in soil. Therefore, VOCs released by Citrobacter sp. appear to be an interesting semiochemical source, mediating interactions with biotic (e.g. animal and human hosts) and abiotic (e.g. water and soil) factors, which is crucial for insects of medical importance [53-56].

The VOC mix released by Citrobacter sp. can be described as having a strong, fetid and putrid odor. Many species among the genus are cataloged within the malodor-generating bacteria group, in part because of their participation in decomposition processes [57-59]. The compounds methanethiol and dimethyl disulfide, identified as VOCs released by C. koseri [43], and the two VOCs used in our study, 2-mercaptoethanol and dimethyl sulfide, are sulfur-containing compounds. Sulfur compounds are neurotoxic and lethal to some insects and are proposed as a new control alternative to agricultural pests $[60,61]$. However, during our tests we did not observe any symptoms of intoxication (i.e. insects with abnormal rest positions, paralysis in the legs, or death [19]) due to sulfur compounds perhaps because of the low doses tested or because the insect never got in direct contact with the compounds tested. Nevertheless, the effects of these sulfur compounds on development, hatching, oviposition or molting of insects, sensory adaptation, or the toxicity to vertebrate animals and humans should be studied for future applications.

Both sulfur compounds, together with 2-phenylethanol, are also known and used as VOC markers of human and animal wastes $[62,63]$. They are also involved in the decomposition of mammal and bird tissues [64, 65], a scenario that is probably not attractive to triatomine insects if that change host volatile profiles of diseased hosts despite the presence of other cues such as temperature and $\mathrm{CO}_{2}$. It should be noted that in this work, the time spent in the host zone when presenting 2-phenylethanol was significantly lower than that of the "host alone" control but not different from the "host plus ethanol" solvent control. Additionally, there were no significant differences between the two controls. This suggests that the repellent effect of 2-phenylethanol is evident only when presented together with ethanol. It is interesting to note that 2-phenylethanol is also produced by the Brindley's glands of T. infestans, which are involved in the production of alarm pheromones in adult insects [66-68]. However, this compound has not been reported as part of the alarm pheromone of $R$. prolixus $[68,69]$. Likewise, in An. gambiae, this compound was reported as a spatial repellent candidate that inhibits attraction $[70,71]$. The effect that this compound could have on the behavior of T. infestans needs to be further assessed.

In this study, DEET was used as a repellent control. Here, the repellency effect of DEET for $R$. prolixus may be the result of an additive effect or synergy between the solvent and DEET, as in the case of 2-phenylethanol. Such a repellency effect of DEET (plus ethanol) was only achieved at the highest dose tested (i.e. 90\%, $50 \mu \mathrm{l}$ ). In contrast, 2-phenylethanol (for $R$. prolixus), dimethyl sulfide (for T. infestans) and 2-mercaptoethanol (for both species) showed a repellent effect at doses two to three orders of magnitude lower than the effective dose of DEET (i.e. 0.003125-0.1\%). Efficiency at low doses is one of the key characteristics that is required for a good, new repellent [25]. The need to employ high concentrations of DEET to achieve repellency has limited its application in disrupting triatomine-human contacts, as several studies have already shown $[15,27-30]$. Although its use is deemed safe, DEET has some disadvantages: it needs to be constantly reapplied; it has a short range of action due to its low volatility and can melt plastics and vinyl $[4,25]$. Even more important, the people who truly need it usually cannot afford it [4]. Repellents for triatomines that are alternative to DEET have recently been proposed [27], 
including 4-methylcyclohexanol, a compound that somewhat resembles 2-phenylethanol. In this work we add up to the list of novel candidate repellents for triatomines.

The question of why triatomines are almost refractory to the gold standard DEET is still open. One hypothesis concerning the repellent effect of DEET is that it mimics a defensive compound of plants, methyl jasmonate, which might explain why this compound is still effective in insects with an evolutionary association with plants, such as mosquitoes [4, 72]. Although some triatomine species such as $R$. prolixus have a close relationship with palm tree niches [73], molecules as DEET may not be directly related to the triatomine evolutive history as early ancestors of the Triatominae subfamily were predators, unlike plant-feeder mosquito ancestors. In fact, triatomines are obligate hematophagous, and many species have nearly no contact with plants [30, 73-75]. Regarding the mechanism of action of synthetic volatiles such as DEET, it has recently been proposed that those compounds decrease the amount of host volatiles reaching the olfactory neurons, changing the chemical profile of hosts [76]. Despite the advances in research on repellency in mosquitoes, where DEET is considered the gold standard, finding efficient repellents for triatomines still represents a challenge and deserves further investigation.

\section{Conclusions}

To the best of our knowledge, this is the first study in triatomines that assesses the repellent effect of individual volatiles of microbial origin from a human host. We showed that vectors of two different tribes (Rhodniini and Triatomini), with epidemiological importance in Chagas disease transmission, are repelled by very low doses of the sulfur compound 2-mercaptoethanol. Future studies should be directed to understand deeply its mechanism of action in triatomines and to assess its possible use as a repellent (although not applied directly onto the skin) maybe within a push-pull vectorial control strategy.

\section{Supplementary information}

Supplementary information accompanies this paper at https://doi. org/10.1186/s13071-020-04013-5.

Additional file 1: Video S1. Video recording showing the repellency effect of the tested compounds on R. prolixus and T. infestans.

\section{Abbreviations}

VOC: Volatile organic compound; DEET: NN-diethyl-3-methylbenzamide.

\section{Acknowledgements}

MR is grateful to Colciencias and Facultad de Ciencias, Universidad de los Andes, for funding this project and fellowship (Convocatoria Nacional para estudios de Doctorados No. 567, and Proyecto Semilla 2018 for Candidate PhD. Students). JM is also grateful to Colciencias (Funding project 759-2013).
PG thanks Lic. Silvia Etcheverry for maintaining the T. infestans colony. We thank two anonymous reviewers for provided helpful comments on earlier drafts of the manuscript.

\section{Authors' contributions}

MR, MIO and JM conceived the idea. MR, MIO, PG and JM contributed to experiments design. MR performed the experiments. MR, MIO, PG and JM contributed to data analyses, interpretation of results and drafted the manuscript. All authors read and approved the final manuscript.

\section{Funding}

This study was prepared from MR's PhD thesis who was supported by Grants from Colciencias (Convocatoria Nacional para estudios de Doctorados No. 567) and Facultad de Ciencias-Universidad de los Andes (Proyecto Semilla 2018 for Candidate PhD Students) (Colombia). This project also was supported by Grants from Colciencias (Funding project 759-2013) to JM and Agencia Nacional de Promoción Científica y Tecnológica (ANPCyT, Argentina) (Grant PICT 2015, No. 3260) to PG. The funding organizations had no role in the design or conduct of this research.

\section{Availability of data and materials}

The datasets used and/or analysed during the study are available from the corresponding author upon reasonable request.

\section{Ethics approval and consent to participate}

According with Colombian laws (Resolución 8430-1993), Ethics Committee from Universidad de los Andes approved the research project and categorized it as a non-risk project (Acta 159-2012).

\section{Consent for publication}

Not applicable.

\section{Competing interests}

The authors declare that they have no competing interests.

\section{Author details}

${ }^{1}$ Centro de Investigaciones en Microbiología y Parasitología Tropical (CIMPAT), Departamento de Ciencias Biológicas, Universidad de los Andes, Bogotá, Colombia. ${ }^{2}$ Laboratorio de Estudio de la Biología de Insectos, Centro de Investigación Científica y de Transferencia Tecnológica a la Producción (CONICETProv. Entre Rios-Uader), Diamante, Argentina. ${ }^{3}$ Facultad de Ingenieria, Universidad Nacional de Entre Ríos, Concepción del Uruguay, Entre Rios, Argentina.

Received: 11 October 2019 Accepted: 10 March 2020

Published online: 18 March 2020

\section{References}

1. WHO. Vector-borne diseases. Geneva: World Health Organization; 2019. https://www.who.int/news-room/fact-sheets/detail/vector-borne-disea ses. Accessed 13 Aug 2019.

2. Centers for Disease Control and Prevention (CDC). Avoid bug bites. 2019. https://wwwnc.cdc.gov/travel/page/avoid-bug-bites. Accessed 14 Aug 2019

3. Environmental Protection Agency United States. Product performance test guidelines OPPTS 810.3700: Insect repellents to be applied to human skin. 2010. https://nepis.epa.gov/Exe/ZyPURL.cgi?Dockey=P100LBO3.txt. Accessed 17 June 2019.

4. Leal WS. The enigmatic reception of DEET—-the gold standard of insect repellents. Curr Opin Insect Sci. 2014;6:93-8.

5. White G, Moore S. Terminology of insect repellents. In: Debboun M, Frances SP, Strickman DA, editors. Insect repellents handbook. 2nd ed. Boca Raton: CRC Press; 2014. p. 3-30.

6. Chagas C. Nova tripanozomiaze humana: estudos sobre a morfolojia e o ciclo evolutivo do Schizotrypanum cruzi n. gen, n. sp., ajente etiolojico de nova entidade morbida do homem. Mem Inst Oswaldo Cruz. 1909;1:159-218.

7. Justi SA, Galvão C. The evolutionary origin of diversity in Chagas disease vectors. Trends Parasitol. 2017;33:42-52. 
8. Rassi A, Rassi A, Marin-Neto JA. Chagas disease. Lancet. 2010;375:1388-402

9. Dorn PL, Justi SA, Dale C, Stevens L, Galvão C, Lima-Cordón R, Monroy C. Description of Triatoma mopan sp. n. from a cave in Belize (Hemiptera, Reduviidae, Triatominae). ZooKeys. 2018;775:69-95.

10. Oliveira J, Ayala JM, Justi SA, da Rosa JA, Galvão C. Description of a new species of Nesotriatoma Usinger, 1944 from Cuba and revalidation of synonymy between Nesotriatoma bruneri (Usinger, 1944) and N. flavida (Neiva, 1911) (Hemiptera, Reduviidae, Triatominae. J Vector Ecol. 2018;43:148-57.

11. Lima-Cordón RA, Monroy MC, Stevens L, Rodas A, Rodas GA, Dorn PL, Justi SA. Description of Triatoma huehuetenanguensis sp. n., a potential Chagas disease vector (Hemiptera, Reduviidae, Triatominae). ZooKeys. 2019;820:51-70.

12. Nascimento JD, Ravazi A, Alevi KCC, Pardo-Diaz C, Salgado-Roa FC, da Rosa JA, et al. Taxonomical over splitting in the Rhodnius prolixus (Insecta: Hemiptera: Reduviidae) clade: are taquarussuensis (da Rosa et al., 2017) and R neglectus (Lent, 1954) the same species? PLoS ONE. 2019;14:e0211285.

13. Gourbière $S$, Dorn $P$, Tripet $F$, Dumonteil E. Genetics and evolution of triatomines: from phylogeny to vector control. Heredity. 2012;108:190-202.

14. WHO. Chagas disease (American trypanosomiasis). Geneva: World Health Organization; 2019. https://www.who.int/en/news-room/fact-sheets/ detail/chagas-disease-(american-trypanosomiasis). Accessed 13 Aug 2019.

15. Zermoglio PF, Martin-Herrou H, Bignon Y, Lazzari CR. Rhodnius prolixus smells repellents: behavioural evidence and test of present and potential compounds inducing repellency in Chagas disease vectors. J Insect Physiol. 2015;81:137-44.

16. Terriquez JA, Klotz SA, Meister EA, Klotz JH, Schmidt JO. Repellency of DEET, picaridin, and three essential oils to Triatoma rubida (Hemiptera: Reduviidae: Triatominae). J Med Entomol. 2013;50:664-7.

17. Zamora D, Klotz SA, Meister EA, Schmidt JO. Repellency of the components of the essential oil, citronella, to Triatoma rubida, Triatoma protracta and Triatoma recurva (Hemiptera: Reduviidae: Triatominae). J Med Entomol. 2015;52:719-21.

18. Lutz A, Sfara V, Alzogaray RA. Repellence produced by monoterpenes on Rhodnius prolixus (Hemiptera: Reduviidae) decreases after continuous exposure to these compounds. J Insect Sci. 2014;14:254.

19. Alzogaray RA, Zerba EN. Rhodnius prolixus intoxicated. J Insect Physiol. 2017:97:93-113.

20. Sfara V, Mougabure-Cueto G, Zerba EN, Alzogaray RA. Adaptation of the repellency response to DEET in Rhodnius prolixus. J Insect Physiol. 2011;57:1431-6.

21. Sfara V, Zerba EN, Alzogaray RA. Fumigant insecticidal activity and repellent effect of five essential oils and seven monoterpenes on first-instar nymphs of Rhodnius prolixus. J Med Entomol. 2009;46:511-5.

22. Lehane MJ. The biology of blood-sucking in insects. 2nd ed. New York: Cambridge University Press; 2005.

23. Benelli G, Pavela R. Beyond mosquitoes-essential oil toxicity and repellency against bloodsucking insects. Ind Crops Prod. 2018;117:382-92.

24. WHO. A global brief on vector-borne diseases. Geneva: World Health Organization; 2014. https://apps.who.int/iris/handle/10665/111008. Accessed 13 Aug 2019.

25. Degennaro M. The mysterious multi-modal repellency of DEET. Fly. 2015;9:45-51.

26. Buescher MD, Rutledge LC, Wirtz RA, Nelson JH. Laboratory repellent tests against Rhodnius prolixus (Heteroptera, Reduviidae). J Med Entomol. 1985;22:49-53.

27. Franco TA, Xu P, Brito NF, Oliveira DS, Wen X, Moreira MF, et al. Reverse chemical ecology-based approach leading to the accidental discovery of repellents for Rhodnius prolixus, a vector of Chagas diseases refractory to DEET. Insect Biochem Mol Biol. 2018;103:46-52.

28. Alzogaray RA, Fontan A, Zerba EN. Repellency of DEET to nymphs of Triatoma infestans. Med Vet Entomol. 2000;14:6-10.

29. Reynoso MMN, Seccacini EA, Calcagno JA, Zerba EN, Alzogaray RA. Toxicity, repellency and flushing out in Triatoma infestans (Hemiptera: Reduviidae) exposed to the repellents DEET and IR3535. PeerJ. 2017;5:e3292.

30. Alzogaray RA. Behavioral and toxicological responses of Rhodnius prolixus (Hemiptera: Reduviidae) to the insect repellents DEET and IR3535. J Med Entomol. 2016;53:387-93.
31. Sfara V, Zerba EN, Alzogaray RA. Toxicity of pyrethroids and repellency of diethyltoluamide in two deltamethrin-resistant colonies of Triatoma infestans Klug, 1834 (Hemiptera: Reduviidae). Mem Inst Oswaldo Cruz. 2006;101:89-94.

32. Sfara V, Zerba EN, Alzogaray RA. Decrease in DEET repellency caused by nitric oxide in Rhodnius prolixus. Arch Insect Biochem Physiol. 2008;67:1-8.

33. Moretti AN, Zerba EN, Alzogaray RA. Behavioral and toxicological responses of Rhodnius prolixus and Triatoma infestans (Hemiptera: Reduviidae) to 10 monoterpene alcohols. J Med Entomol. 2013;50:1046-54.

34. Lima B, López S, Luna L, Agüero MB, Aragón L, Tapia A, et al. Essential oils of medicinal plants from the Central Andes of Argentina: chemical composition, and antifungal, antibacterial, and insect-repellent activities. Chem Biodivers. 2011;8:924-36.

35. Sainz P, Sanz J, Burillo J, González-Coloma A, Bailén M, Martínez-Díaz RA. Essential oils for the control of reduviid insects. Phytochem Rev. 2012;11:361-9.

36. Moretti AN, Zerba EN, Alzogaray RA. Lethal and sublethal effects of eucalyptol on Triatoma infestans and Rhodnius prolixus, vectors of Chagas disease. Entomol Exp Appl. 2015;154:62-70.

37. Braks MAH, Anderson RA, Knols BGJ. Infochemicals in mosquito host selection: human skin microflora and Plasmodium parasites. Parasitol Today. 1999;15:409-13.

38. De Jong R, Knols BGJ. Selection of biting sites on man by two malaria mosquito species. Experientia. 1995;51:80-4.

39. Verhulst NO, Qiu YT, Beijleveld H, Maliepaard C, Knights D, Schulz S, et al. Composition of human skin microbiota affects attractiveness to malaria mosquitoes. PLoS ONE. 2011;6:e28991.

40. Verhulst NO, Takken W, Dicke M, Schraa G, Smallegange RC. Chemical ecology of interactions between human skin microbiota and mosquitoes. FEMS Microbiol Ecol. 2010;74:1-9.

41. Smallegange RC, Verhulst NO, Takken W. Sweaty skin: an invitation to bite? Trends Parasitol. 2011;27:143-8.

42. Braks MAH, Takken W. Incubated sweat but not fresh sweat attracts the malaria mosquito, Anopheles gambiae sensu stricto. J Chem Ecol. 1999;25:663-72.

43. Tabares M, Ortiz M, Gonzalez M, Carazzone C, Vives Florez MJ, Molina J. Behavioral responses of Rhodnius prolixus to volatile organic compounds released in vitro by bacteria isolated from human facial skin. PLoS Negl Trop Dis. 2018;12:e0006423.

44. Ortiz MI, Suárez-Rivillas A, Molina J. Behavioural responses to human skin extracts and antennal phenotypes of sylvatic first filial generation and long rearing laboratory colony Rhodnius prolixus. Mem Inst Oswaldo Cruz. 2011;106:461-6.

45. Ortiz MI, Molina J. Preliminary evidence of Rhodnius prolixus (Hemiptera: Triatominae) attraction to human skin odour extracts. Acta Trop. 2010;113:174-9.

46. Wigglesworth V, Gillett J. The function of the antennae in Rhodnius prolixus (Hemiptera) and the mechanism of orientation to the host. J Exp Biol. 1934;120-39.

47. Lazzari CR, Núñez J. The response to radiant heat and the estimation of the temperature of distant sources in Triatoma infestans. J Insect Physiol. 1989.35:525-9.

48. Doran TI. The role of Citrobacter in clinical disease of children: review. Clin Infect Dis. 1999;28:384-94.

49. Netsvyetayeva I, Marusza W, Olszanski R, Szyller K, Krolak-Ulinska A, Swoboda-Kopec E, et al. Skin bacterial flora as a potential risk factor predisposing to late bacterial infection after cross-linked hyaluronic acid gel augmentation. Infect Drug Resist. 2018;11:213-22.

50. Ponnusamy L, Schal C, Wesson DM, Arellano C, Apperson CS. Oviposition responses of Aedes mosquitoes to bacterial isolates from attractive bamboo infusions. Parasit Vectors. 2015;8:486.

51. Conway MJ, Colpitts TM, Fikrig E. Role of the vector in arbovirus transmission. Annu Rev Virol. 2014;1:71-88.

52. Romero A, Broce A, Zurek L. Role of bacteria in the oviposition behaviour and larval development of stable flies. Med Vet Entomol. 2006;20:115-21.

53. Ross AA, Rodrigues Hoffmann A, Neufeld JD. The skin microbiome of vertebrates. Microbiome. 2019;7:79.

54. Leroy PD, Sabri A, Verheggen FJ, Francis F, Thonart P, Haubruge E. The semiochemically mediated interactions between bacteria and insects. Chemoecology. 2011;21:113-22. 
55. Schulz S, Dickschat JS. Bacterial volatiles: the smell of small organisms. Nat Prod Rep. 2007;24:814-42.

56. Davis TS, Crippen TL, Hofstetter RW, Tomberlin JK. Microbial volatile emissions as insect semiochemicals. J Chem Ecol. 2013;39:840-59.

57. Troccaz M, Niclass Y, Anziani P, Starkenmann C. The influence of thermal reaction and microbial transformation on the odour of human urine. Flavour Fragr J. 2013;28:200-11.

58. Goldberg S, Cardash H, Browning H, Sahly H, Rosenberg M. Isolation of Enterobacteriaceae from the mouth and potential association with malodor. J Dent Res. 1997;76:1770-5.

59. Pascual J, von Hoermann C, Rottler-Hoermann A, Nevo O, Geppert A, Sikorski J, et al. Function of bacterial community dynamics in the formation of cadaveric semiochemicals during in situ carcass decomposition. Environ Microbiol. 2017;19:3310-22.

60. Dugravot S, Grolleau F, Macherel D, Rochetaing A, Hue B, Stankiewicz $M$, et al. Dimethyl disulfide exerts insecticidal neurotoxicity through mitochondrial dysfunction and activation of insect K ATP channels. J Neurophysiol. 2003;90:259-70.

61. Dugravot S, Sanon A, Thibout E, Huignard J. Susceptibility of Callosobruchus maculatus (Coleoptera: Bruchidae) and its parasitoid Dinarmus basalis (Hymenoptera: Pteromalidae) to sulphur-containing compounds: consequences on biological control. Environ Entomol. 2002;31:550-7.

62. Moore JG, Jessop LD, Osborne DN. Gas-chromatographic and massspectrometric analysis of the odor of human feces. Gastroenterology. 1987;93:1321-9.

63. Sato H, Hirose T, Kimura T, Moriyama Y, Nakashima Y. Analysis of malodorous volatile substances of human waste: feces and urine. J Heal Sci. 2001;47:483-90.

64. Zhu JJ, Chaudhury MF, Tangtrakulwanich K, Skoda SR. Identification of oviposition attractants of the secondary screwworm, Cochliomyia macellaria (F.) released from rotten chicken liver. J Chem Ecol. 2013:39:1407-14.

65. Okunuga $\bigcirc$. Analysis of volatile organic compounds produced during the decomposition of human analogues. PhD thesis, University of Leicester, UK; 2016. http://hdl.handle.net/2381/39915. Accessed 17 June 2019.

66. Cruz-López L, Morgan ED, Ondarza RN. Brindley's gland exocrine products of Triatoma infestans. Med Vet Entomol. 1995:9:403-6.
67. Audino PG, Alzogaray RA, Vassena C, Masuh H, Fontán A, Gatti P, et al. Volatile compounds secreted by Brindley's glands of adult Triatoma infestans: identification and biological activity of previously unidentified compounds. J Vector Ecol. 2008;32:75-82.

68. Guerenstein PG, Guerin PM. A comparison of volatiles emitted by adults of three triatomine species. Entomol Exp Appl. 2004;111:151-5.

69. Barrozo RB, Reisenman CE, Guerenstein P, Lazzari CR, Lorenzo MG. An inside look at the sensory biology of triatomines. J Insect Physiol. 2017;97:3-19.

70. Smallegange RC, Bukovinszkiné-Kiss G, Otieno B, Mbadi PA, Takken W, Mukabana WR, et al. Identification of candidate volatiles that affect the behavioural response of the malaria mosquito Anopheles gambiae sensu stricto to an active kairomone blend: laboratory and semi-field assays. Physiol Entomol. 2012;37:60-71.

71. Verhulst NO, Mbadi PA, Kiss GB, Mukabana WR, Van Loon JJA, Takken W, et al. Improvement of a synthetic lure for Anopheles gambiae using compounds produced by human skin microbiota. Malar J. 2011;10:28

72. Xu P, Choo YM, De La Rosa A, Leal WS. Mosquito odorant receptor for DEET and methyl jasmonate. Proc Natl Acad Sci USA. 2014;111:16592-7.

73. Lent $\mathrm{H}$, Wygodzinsky P. Revision of the Triatominae (Hemiptera, Reduviidae), and their significance as vectors of Chagas' disease. Bull Am Museum Nat Hist. 1979;163:123-520.

74. Otálora-Luna F, Pérez-Sánchez AJ, Sandoval C, Aldana E. Evolution of hematophagous habit in Triatominae (Heteroptera: Reduviidae). Rev Chil Hist Nat. 2015:88:4.

75. Mans BJ. Evolution of vertebrate hemostatic and inflammatory control mechanisms in blood-feeding arthropods. J Innate Immun. 2011;3:41-51.

76. Afify A, Betz JF, Riabinina O, Lahondère C, Potter CJ. Commonly used insect repellents hide human odors from Anopheles mosquitoes. Curr Biol. 2019;29:3669-80.

\section{Publisher's Note}

Springer Nature remains neutral with regard to jurisdictional claims in published maps and institutional affiliations.
Ready to submit your research? Choose BMC and benefit from:

- fast, convenient online submission

- thorough peer review by experienced researchers in your field

- rapid publication on acceptance

- support for research data, including large and complex data types

- gold Open Access which fosters wider collaboration and increased citations

- maximum visibility for your research: over $100 \mathrm{M}$ website views per year

At BMC, research is always in progress.

Learn more biomedcentral.com/submissions 